\title{
Evaluation of oxidative stress-induced diabetic complications on alloxan-treated hyperglycaemic rats, using some biochemical parameters and histological profiles of three major organs
}

\begin{abstract}
Background: Oxidative Stress evaluation is fast becoming a diagnostic tool in many disease conditions affecting man. This study evaluated oxidative stress on alloxaninduced diabetic rats by measuring serum Gamma-Glutamyl Transferase (GGT). Total Antioxidant Content (TAC), Lipid Profile, Fasting Plasma Glucose, Transaminases (ALT, AST). Methods: 40 albino Wistar rats of both sexes weighing $190 \pm 20 \mathrm{~g}$ were used for this study. The animals were randomly assigned into two groups A and B consisting of twenty rats each. Group A was the control (non-diabetic) group, while Group B was the experimentally-induced diabetic group. The study lasted for five weeks and blood samples were collected at the third and fifth weeks for some biochemical studies. The following biochemical parameters: Fasting Plasma Glucose (FPG) Serum Urea Creatinine, Alanine and Aspartate Transaminases (ALT, AST) Lipid profile, GammaGlutamyl Transferase (GGT) and Total Anti-oxidant Content (TAC) were measured according to standard methods. Histological examinations of major organs - heart, kidneys, and liver - were made according to standard methods.

Results: There were significant differences between the groups in the biochemical parameters $(p>0.05)$ and the histological examinations at weeks 3 and 5 . The mean serum GGT concentration of the diabetic group at 3 and 5 weeks $(4.0 \pm 0.2 \mathrm{iu} / 1$ and $4.4 \pm 0.2 \mathrm{iu} / 1$ respectively) were significantly increased $(\mathrm{p}<0.001)$ when compared to the control group $0.8 \pm 0.2 \mathrm{iu} / 1$ and $0.8 \pm 0.1 \mathrm{iu} / 1$ at 3 and 5 weeks respectively while the mean serum TAC of the diabetic group at 3 and 5 weeks $(0.8 \pm 0.1 \mathrm{mmol} / 1$ and $0.6 \pm 0.1 \mathrm{mmol} / 1)$ respectively were significantly decreased $(\mathrm{p}<0.001)$ when compared to the control $1.6 \pm 0.1 \mathrm{mmol} / 1$ and $1.7 \pm 0.1 \mathrm{mmol} / 1$ at 3 and 5 weeks respectively. The mean Urea, Creatinine, ALT, AST, TC, LDL-C, VLDL-C, TG, FPG and HbA1c values were significantly increased $(\mathrm{p}<0.001)$ in the diabetic group when compared to the control group while the mean serum HDL-C value of the diabetic group decreased significantly $(\mathrm{p}<0.001)$ when compared with the control at 3 and 5 weeks of the study. Histological examinations showed mild structural distortions of the organs studied in the experimental group.

Interpretation: The present study shows that alloxan injection caused a significant increase in plasma glucose levels in rats in comparison with the control rats. Persistent hyperglycaemia resulted in a number of biochemical and pathological changes in the diabetic rats but the control rats were normoglycaemic and showed no biochemical or pathological changes . There was a correlation between GGT and TAC, indicative of oxidative stress on the diabetic rats.
\end{abstract}

Keywords: alloxan, biochemical parameter, diagnostics, histological profile, hyperglycaemia, oxidative stress
Volume 4 Issue 2 - 2018

\author{
Nwando C Obi-Ezeani,' Fred C Otuu, ${ }^{2,3}$ Joel \\ C Onyeanwusi, ${ }^{4}$ Elvis N Shub, ${ }^{2,6}$ Inya-Agha S \\ Ifeoma, ${ }^{5}$ Tilako B Halilu, ${ }^{6}$ Sunday ENwodo ${ }^{7}$ \\ 'Department of Chemical Pathology, Chukwuemeka Odumegwu \\ Ojukwu University, Nigeria \\ ${ }^{2}$ Department of Pharmacology \& Therapeutics, University of \\ Nigeria, Nigeria \\ ${ }^{3}$ Department of Pharmaceutics, University of Nigeria, Nigeria \\ ${ }^{4}$ Department of Medical Laboratory Sciences, University of \\ Nigeria, Nigeria \\ ${ }^{5}$ Department of Pharmacognosy and Environmental Medicine, \\ University of Nigeria, Nigeria \\ ${ }^{6}$ Gombe State Ministry of Health, Nigeria \\ ${ }^{7}$ Department of Pharmacology \& Therapeutics, University of \\ Nigeria, Nigeria
}

Correspondence: Fred C Otuu, Molecular and Environmental Research Group, Department of Pharmacology \& Therapeutics, College of Medicine, University of Nigeria, Enugu Campus, Enugu State, Nigeria, Tel +2347 03245422 2, Email Fred.otuu@unn.edu.ng

Received: February 07, 2018 | Published: March 14, 2018

\section{Introduction}

Diabetes mellitus often simply referred to as diabetes is one of the most important health problems with very high prevalence, morbidity and mortality. It is a group of metabolic diseases characterized by chronic hyperglycaemia resulting from defects in insulin secretion, action or both. ${ }^{1}$ Insulin is a hormone produced by the pancreas that allows glucose from food to enter the body's cells where it is converted into energy needed for muscles and tissues to function. As a result, a person with diabetes does not absorb glucose properly, and glucose stays circulating in the blood (hyperglycaemia) damaging tissues over time. This damage leads to life threatening health complications. ${ }^{2}$ Diabetes is the world's largest endocrine disorder with deranged carbohydrate, fat and protein metabolism. ${ }^{3}$ The World Health Organization in 2002 predicted that the worldwide number of patients with diabetes will double by the year 2025, from the current number of approximately 150 million to 300 million. Uncontrolled or poorly controlled diabetes increases both short and long term complications like micro- and macrovascular complications. The most common complications are atherosclerosis, nerve damage, renal failure, blindness, infertility and so on. The liver has also been shown to be affected by diabetes, although the exact mechanism still remains unclear. ${ }^{4}$ Alloxan is a diabetogenic agent used to induce experimental model of diabetes. Administration of alloxan to different 
animals produces necrosis of the islets, several features common to those observed in human diabetes. ${ }^{5}$ Animal models of diabetes are increasingly being used in the investigation of the pathogenesis of diabetes and long term diabetic complications seen in clinical studies. ${ }^{6}$ Diabetes mellitus results in multi-system consequences which present with biochemical and anatomical changes. Disturbances in the metabolism of carbohydrates, proteins and fats are the biochemical consequences, while micro-and macrovascular complications are the anatomical derangements. Increasing evidence in both experimental and clinical studies suggest that oxidative stress plays a role in the pathogenesis of diabetes mellitus, and the free radicals formed as a result leads to a decline in the anti-oxidant defense mechanism which consequently lead to increased risk and development of complications of diabetes, all of which affect longevity and quality of life. Moreover, accumulating evidence suggests that oxidative stress plays a pivotal role in the aetiology of diabetic complications. Living organisms have developed complex antioxidant systems to counteract reactive species and to reduce their damage. These antioxidant systems include enzymes such as catalase, superoxide dismutase and glutathione peroxidase; macromolecules such as albumin, ceruroplasmin and ferritin, and an array of small molecules, including ascorbic acid, $\alpha$-tocopherol, $\beta$-carotene, ubiquinol-10, reduced glutathione (GSH), methionine, uric acid and bilirubin. ${ }^{7,8}$ The Total Antioxidant Concentration (TAC) serves as a general marker of the antioxidant defenses. In vitro and clinical studies may provide additional useful ways to probe the inter connections of oxidative stress and diabetes, and there is a need to continue to explore the mechanisms by which increased oxidative stress accelerates the development of complications in diabetes. ${ }^{9}$

\section{Methods}

\section{Experimental animals}

40 albino Wistar rats of both sexes weighing between $190 \mathrm{~g} \pm 20 \mathrm{~g}$ were used for this study. The animals were maintained on a standard poultry diet (Vital Feeds, Jos) and water ad libitum, and were allowed an acclimatization period of two weeks. They were handled according to the institutional and international guidelines for the care and use of laboratory animals.

\section{Experimental design}

The animals were randomly assigned into two groups A and B consisting of twenty rats each. Group A was the control (non-diabetic) group, while Group B was the experimentally-induced diabetic group.

\section{Induction of experimental diabetes}

After an overnight fast, experimental diabetes was induced in group $\mathrm{B}$ animals by a single intraperitoneal dose of alloxan monohydrate at $150 \mathrm{mg} / \mathrm{kg}$ body weight dissolved in freshly prepared normal saline while those in group A were given normal saline intraperitoneally after an overnight fast. Development of diabetes was confirmed one week post-alloxan administration in Group B after an overnight fast by measuring the fasting plasma glucose (FPG) levels using a commercial glucose kit (Randox). Only rats with FPG above $11 \mathrm{mmol} / 1$ were included in this study. On the 3rd and 5th weeks respectively, 10 rats from each group were fasted overnight, euthanized, and blood samples collected through cardiac puncture for the estimation of biochemical parameters and organs excised for histological studies. The body weights of the rats were measured using a spring balance before and at the end of the experiment.

\section{Biochemical assays}

Blood samples were collected in three different test tubes; fluoride oxalate tube for the estimation of plasma glucose, plain tubes (without anticoagulants) to separate serum for estimation of some biochemical parameters and EDTA tubes for glycated haemoglobin (HbA1c) estimation. Blood samples in fluoride oxalate and plain tubes were centrifuged in Techmel and Techmel $800 \mathrm{D}$ centrifuge USA at $3000 \mathrm{~g}$ for 5 and 10 minutes respectively. The supernatant plasma was used for FPG assay while the serum was used for urea, creatinine, ALT, AST, lipid profile, GGT and TAC assay.

\section{FPG assay}

This was done using the glucose oxidase method as described by Trinder et al. ${ }^{9} 1000 \mu \mathrm{l}$ of the working reagent (Randox kit) was added to $10 \mu \mathrm{l}$ of sample and standard, this was mixed and incubated for 20 minutes at $25{ }^{\circ} \mathrm{C}$ (room temperature) and absorbance of sample and standard were measured against the reagent blank at $520 \mathrm{~nm}$.

\section{Urea assay}

The diacetylmonoxime (DAM) method was used. DAM was hydrolyzed to diacetyl and monoxime in a hot acid medium, diacetyl condensed with urea to form a pink coloured complex whose intensity was proportional to the urea concentration. $2000 \mu$ l each of the mixed acid and colour were added to $10 \mu$ of sample, standard, mixed and incubated at $100 \mathrm{oC}$ for 10 minutes. Absorbance of sample and standard were read at $540 \mathrm{~nm}$ after cooling.

\section{Creatinine assay}

This was according to Jaffe's method as modified by Fabing \& Ertingshaushen et al. ${ }^{10} 1500 \mu \mathrm{l}$ of distilled water was added to $500 \mu \mathrm{l}$ of both serum and standard while $2000 \mu \mathrm{l}$ of distilled water was added to the blank. $1000 \mu$ leach of $\mathrm{H} 2 \mathrm{SO} 4$ and sodium tungstate were added to sample, standard and blank, incubated at room temperature and then centrifuged for 10 minutes. $500 \mu \mathrm{l}$ each of $\mathrm{NaOH}$ and picric acid were added to $1500 \mu$ l of the supernatant incubated at room temperature for 15 minutes and read at $490 \mathrm{~nm}$.

\section{Alanine and aspartate transaminases (ALT \& AST)}

This was estimated according to the method described by Rietman \& Frankel et al. ${ }^{11} 500 \mu \mathrm{l}$ each of ALT and AST substrates were incubated for 5 minutes at $37^{\circ} \mathrm{C}$ (for Test and Blank). $100 \mu \mathrm{l}$ and $200 \mu \mathrm{l}$ of test samples were added to the ALT and AST substrates respectively, mixed and incubated for 30 minutes at $37^{\circ} \mathrm{C}$. $500 \mu 1$ of 2,4-DNPH was added to both Test and Blank. For the Blank sample, $100 \mu$ and $200 \mu 1$ of samples were added as in Test above to the substrate/DNPH mixture and incubated for 20 minutes at room temperature. $5000 \mu \mathrm{l}$ of $\mathrm{NaOH}$ was added to both Test and Blank, and absorbance read at $540 \mathrm{~nm}$.

\section{Total cholesterol (TC) assay}

This was estimated as described by Richmond \& Roeschlau et al. ${ }^{12,13} 1000 \mu \mathrm{l}$ of cholesterol reagent (Randox kit) was added to $10 \mu \mathrm{l}$ each of the sample and standard, mixed and incubated for 10 minutes at room temperature. The absorbances were measured against the reagent blank at $540 \mathrm{~nm}$. 


\section{High density lipoprotein cholesterol (HDL-C) assay}

This was measured using the method of Wacnic \& Alber et al. ${ }^{14}$ $500 \mu$ of diluted precipitant and $200 \mu 1$ of sample and standard were mixed and incubated for 10 minutes at room temperature, then centrifuged for 10 minutes. $1000 \mu$ of cholesterol reagent (Randox kit) was added to $10 \mu \mathrm{l}$ each of the supernatant and standard, mixed and incubated for 10 minutes at room temperature, then read colorimetrically at $540 \mathrm{~nm}$.

\section{Triglyceride (TG) assay}

This was estimated according to the method described by Tietz et al. ${ }^{15} 1000 \mu$ l of the TG reagent (Randox kit) was added to $10 \mu$ each of sample and standard, incubated for 10 minutes at room temperature, and absorbance read at $540 \mathrm{~nm}$.

\section{Low density lipoprotein cholesterol (LDL-C) assay}

This was calculated in $\mathrm{mmol} / \mathrm{l}$ using the Friedewald's equation as stated below: ${ }^{16}$

$$
L D L-C=T C-(H D L-C+T G / 2.2) .
$$

\section{Very low density lipoprotein cholesterol (VLDL-C) assay}

This was also calculated in mmol/l using the Friedewald's equation as stated below: ${ }^{16}$

$$
V L D L-C=T G
$$

\section{Gamma-glutamyl transferase (GGT) assay}

This was measured as described by Persijn \& Gendler et al. ${ }^{17,18}$ Samples were analyzed using Mindray BS-120 auto analyser and colour intensity measured photometrically.

\section{Total antioxidant concentration (TAC) assay}

The TAC of serum was estimated as described by Koracevic et al. ${ }^{19}$ Six test tubes labeled sample (A1), sample blank (A0), negative control (K1 and K0) and standard (UA1 and UA0) were used, in which each sample was analyzed in six (6) runs with negative control for each series of analysis prepared in duplicate containing the same reagents as $\mathrm{A} 1$ and $\mathrm{A} 0$ except for serum. $10 \mu \mathrm{l}$ of serum was added to $\mathrm{A} 1$ and $\mathrm{A} 0,10 \mu \mathrm{l}$ of uric acid was added to UA1 and UA0 after which $490 \mu 1$ of buffer, $50 \mu 1$ of sodium benzoate, $200 \mu 1$ of iron-EDTA and $200 \mu \mathrm{l}$ of hydrogen peroxide were added to A1, A0, K1, K0, UA1 and UA0. $1000 \mu 1$ of acetic acid was then added to A0, K0 and UA0. The solutions were mixed and incubated at $37^{\circ} \mathrm{C}$ before adding $1000 \mu \mathrm{l}$ of acetic acid to $\mathrm{A} 1, \mathrm{~K} 1$ and $\mathrm{UA} 1$, and $1000 \mu \mathrm{l}$ of thiobarbituric acid to $\mathrm{A} 1, \mathrm{~A} 0, \mathrm{~K} 1, \mathrm{~K} 0$, UA1 and UA0.

\section{Glycated haemoglobin (HbAlc) assay}

This was measured in whole blood using the micro-column chromatography method as described by Bissé \& Abragam. ${ }^{20}$ The columns and reagents were brought to room temperature. $50 \mu \mathrm{l}$ blood and $200 \mu \mathrm{l}$ reagent 1 were mixed (haemolysate) and incubated for 15 minutes at room temperature. $50 \mu \mathrm{l}$ of haemolysate and $200 \mu \mathrm{l}$ reagent 2 were added to each column and left to drain to waste. The columns were then placed over new test tubes and $4 \mathrm{ml}$ reagent 3 was added, and the absorbance of the eluate (AHbA1c) collected read at $415 \mathrm{~nm} .12 \mathrm{ml}$ reagent 3 and $50 \mu$ of haemolysate were mixed and the absorbance (AHb Total) read at same wavelength.

\section{Histological examinations}

All tissues were fixed in $10 \%$ formalin, the fixed tissues were dehydrated with grades of alcohol beginning from $70 \%$ to absolute. They were then cleared with xylene, impregnated and embedded in paraffin wax. Sections were prepared, stained with haematoxylin and eosin (H\&E) stain, and then mounted using DPX (Distrene 80 dibutylphthalate Xylene) for light microscopy and photomicrography.

\section{Statistical analyses}

Values obtained were expressed as mean \pm standard error of mean. The data were analysed using the Statistical Package for Social Sciences (SPSS) version 17.0 software, and a p-value of $<0.05$ was considered statistically significant.

\section{Results}

The results of this study are presented in Tables $1-4$. Table 1 shows the mean body weights (initial and final) of the experimental groups at 3 and 5 weeks. There was no statistically significant difference $(\mathrm{p}>0.05)$ in the means of initial body weights of groups A and B $(184.0 \pm 4.5 \mathrm{~g}$ and $188.0 \pm 5.7 \mathrm{~g})$ at 3 weeks, and $182.0 \pm 5.5 \mathrm{~g}$ and 185.0 $\pm 4.8 \mathrm{~g}$ at 5 weeks respectively while the means of the final body weights of groups A and B $(198.0 \pm 4.2 \mathrm{~g}$ and $172.0 \pm 4.7 \mathrm{~g})$ at 3 weeks, and $207.0 \pm 5.4 \mathrm{~g}$ and $153.0 \pm 4.0 \mathrm{~g}$ at 5 weeks respectively showed a statistically significant difference $(\mathrm{p}<0.05)$ There was a significant increase in the body weights of the control group while the diabetic group showed a significant decrease in their body weights. In Table 2 , the mean serum GGT concentration of the diabetic group at 3 and 5 weeks $(4.0 \pm 0.2 \mathrm{iu} / 1$ and $4.4 \pm 0.2 \mathrm{iu} / 1$ respectively) were significantly increased $(p<0.001)$ when compared to the control group $0.8 \pm 0.2 \mathrm{iu} / 1$ and $0.8 \pm 0.1 \mathrm{iu} / 1$ at 3 and 5 weeks respectively while the mean serum TAC of the diabetic group at 3 and 5 weeks $(0.8 \pm 0.1 \mathrm{mmol} / 1$ and $0.6 \pm 0.1 \mathrm{mmol} / 1)$ respectively were significantly decreased $(\mathrm{p}<0.001)$ when compared to the control $1.6 \pm 0.1 \mathrm{mmol} / 1$ and $1.7 \pm 0.1 \mathrm{mmol} / 1$ at 3 and 5 weeks respectively. Table 3 shows the correlation coefficient between GGT and TAC at 3 and 5 weeks. There was a significant $(\mathrm{p}<0.001)$ negative correlation between GGT and TAC in the experimental groups, $r=-0.707$ and $r=-0.897$ at 3 and 5 weeks respectively. In Table 4, the mean Urea, Creatinine, ALT, AST, TC, LDL-C, VLDL-C, TG, FPG and HbAlc values were significantly increased $(p<0.001)$ in the diabetic group when compared to the control group while the mean serum HDL-C value of the diabetic group decreased significantly $(\mathrm{p}<0.001)$ when compared to the control at 3 and 5 weeks of the study.

Table I Body weights of non-diabetic and diabetic rats at 3 and 5 weeks

\begin{tabular}{lll}
\hline Group & Initial weight $(\mathrm{g})$ & Final weight $(\mathrm{g})$ \\
\hline $\mathrm{A}(3$ weeks $)$ & $184.0 \pm 4.5$ & $198.0 \pm 4.2$ \\
$\mathrm{~B}$ (3 weeks) & $188.0 \pm 5.7$ & $172.0 \pm 4.7$ \\
p-value & $>0.05$ & $<0.05$ \\
A(5 weeks) & $182.0 \pm 5.5$ & $207.0 \pm 5.4$ \\
B(5 weeks) & $185.0 \pm 4.8$ & $153.0 \pm 4.0$ \\
p-value & $>0.05$ & $<0.05$
\end{tabular}


Table 2 Serum GGT and TAC levels of non-diabetic and diabetic rats at 3 and 5 weeks

\begin{tabular}{lll}
\hline Group & GGT $(\mathbf{i u} / \mathbf{l})$ & TAC $(\mathbf{m m o l} / \mathbf{l})$ \\
\hline A(3 weeks) & $0.8 \pm 0.2$ & $1.6 \pm 0.1$ \\
B(3 weeks) & $4.0 \pm 0.2$ & $0.8 \pm 0.1$ \\
p-value & $<0.001$ & $<0.001$ \\
A(5 weeks) & $0.8 \pm 0.1$ & $1.7 \pm 0.1$ \\
B(5 weeks) & $4.4 \pm 0.2$ & $0.6 \pm 0.1$ \\
p-value & $<0.001$ & $<0.001$ \\
\hline
\end{tabular}

Table 3 Correlation coefficient between GGT and TAC of experimental groups at 3 and 5 weeks

\begin{tabular}{lll}
\hline Parameters & Correlation coefficient (r-value) & p-value \\
\hline GGT and TAC(3 weeks) & -0.707 & $<0.001$ \\
GGT and TAC(5 weeks) & -0.897 & $<0.001$
\end{tabular}

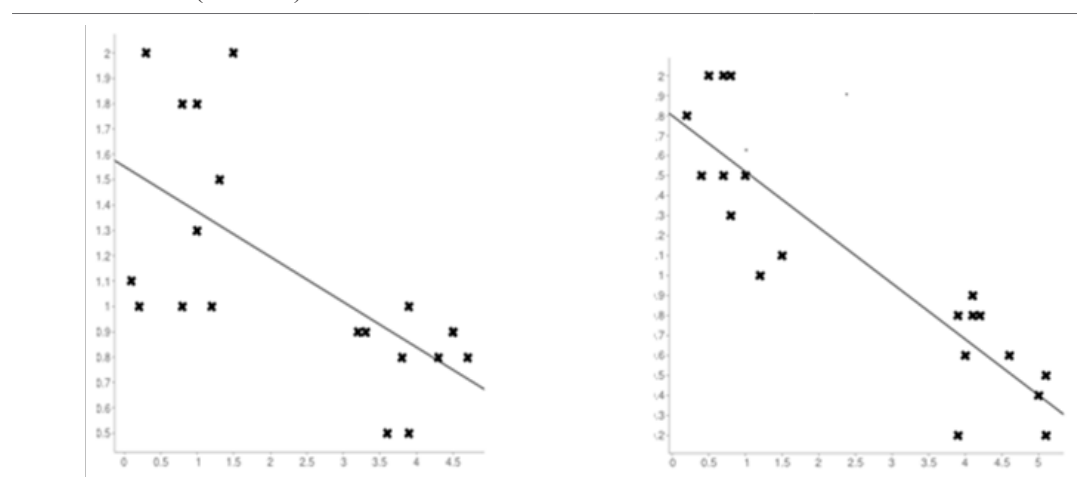

Table 4 Test for kidney function (urea \& creatinine), liver function (ALT \& AST), lipid profile (TC, HDLC, LDLC,VLDLC,TG) and carbohydrate metabolism (FPG \& HBLC) of non- diabetic and diabetic rats at 3 and 5 weeks

\begin{tabular}{|c|c|c|c|c|c|c|c|c|c|c|c|}
\hline Group & $\begin{array}{l}\text { Urea } \\
\text { mmol/l }\end{array}$ & $\begin{array}{l}\text { Crea } \\
\mu \mathrm{mol} / \mathrm{l}\end{array}$ & ALT iu/l & AST iu/l & $\begin{array}{l}\mathrm{TC} \\
\mathrm{mmol} / \mathrm{l}\end{array}$ & $\begin{array}{l}\text { HDLC } \\
\mathrm{mmol} / \mathrm{l}\end{array}$ & $\begin{array}{l}\text { LDLC } \\
\mathrm{mmol} / \mathrm{l}\end{array}$ & $\begin{array}{l}\text { VLDLC } \\
\mathrm{mmol} / \mathrm{l}\end{array}$ & $\begin{array}{l}\text { TG } \\
\mathrm{mmol} / \mathrm{l}\end{array}$ & $\begin{array}{l}\text { FPG } \\
\mathrm{mmol} / \mathrm{l}\end{array}$ & $\begin{array}{l}\text { HbA1c } \\
\%\end{array}$ \\
\hline $\mathrm{A}(3 \mathrm{wks})$ & $4.4 \pm 0.5$ & $96.5 \pm 1.6$ & $13.3 \pm 1.0$ & $18.1 \pm 1.1$ & $2.3 \pm 0.1$ & $1.2 \pm 0.0$ & $0.6 \pm 0.1$ & $0.5 \pm 0.0$ & $1 \pm 0.0$ & $5 \pm 0.1$ & $3.8 \pm 0.1$ \\
\hline $\mathrm{B}(3 \mathrm{wks})$ & $10.4 \pm 0.3$ & $132.6 \pm 2.0$ & $22.4 \pm 0.8$ & $29.2 \pm 1.5$ & $3.8 \pm 0.1$ & $0.6 \pm 0.0$ & $2.3 \pm 0.1$ & $1 \pm 0.0$ & $2.3 \pm 0.0$ & $14.4 \pm 0.1$ & $9.1 \pm 0.5$ \\
\hline p-value & $<0.001$ & $<0.001$ & $<0.001$ & $<0.001$ & $<0.001$ & $<0.001$ & $<0.001$ & $<0.001$ & $<0.001$ & $<0.001$ & $<0.001$ \\
\hline $\mathrm{A}(5 \mathrm{wks})$ & $4.8 \pm 0.5$ & $97.4 \pm 1.4$ & $13 \pm 1.1$ & $17.3 \pm 1.1$ & $2.4 \pm 0.1$ & $1.3 \pm 0.0$ & $0.7 \pm 0.0$ & $0.5 \pm 0.0$ & $1.1 \pm 0.0$ & $5.1 \pm 0.1$ & $3.9 \pm 0.1$ \\
\hline $\mathrm{B}(5 \mathrm{wks})$ & $10.8 \pm 0.3$ & $138 \pm 2.0$ & $24.2 \pm 0.9$ & $32 \pm 1.5$ & $3.7 \pm 0.1$ & $0.6 \pm 0.0$ & $2.1 \pm 0.0$ & $1.1 \pm 0.0$ & $2.4 \pm 0.0$ & $13.2 \pm 0.3$ & $10.1 \pm 0.7$ \\
\hline p-value & $<0.001$ & $<0.001$ & $<0.001$ & $<0.001$ & $<0.001$ & $<0.001$ & $<0.001$ & $<0.001$ & $<0.001$ & $<0.001$ & $<0.001$ \\
\hline
\end{tabular}

\section{Interpretation}

The present study shows that alloxan injection caused a significant increase in plasma glucose levels in rats in comparison with the control rats. Persistent hyperglycaemia resulted in a number of biochemical and pathological changes in the diabetic rats but the control rats were normoglycaemic and showed no biochemical or pathological changes. This agrees favourably with the results of Gidado et al., ${ }^{21}$ Gwarzo et al., ${ }^{22}$ Enas $^{23}$ who reported that intraperitoneal injection of alloxan induced diabetes. In the present study, the alloxan induced diabetic rats showed significantly higher levels of FPG and lower body weights when compared to the control. This was consistent with earlier reports of Komolafe et al.; ${ }^{24}$ Murali et al.;25 Urmila \& Goyal. ${ }^{26}$ Previous histological studies also supported the present investigation as alloxan was suspected to destroy the B cell islets of Langerhaans according to the reports of Sandhu et al., ${ }^{27}$ Szkudelski, ${ }^{28}$ Mir et al., ${ }^{29}$ Muthulingam; ${ }^{30}$ who reported that the pancreas of alloxan or streptozotocin induced diabetic rats showed reduced islet cells and necrosis. The pancreas is especially susceptible to action of alloxan induced free radical damage leading to massive reduction of insulin release, the resultant effect which is insulin deficiency leads to increased blood glucose and a host of other metabolic alterations in the animals. The weights of the diabetic rats were significantly reduced despite the increase in food and fluid intake in these animals. The weight loss was progressive for five weeks post alloxan administration. The reduction in body weights observed in the diabetic rats compared to the non-diabetic rats may be due to dehydration and increased catabolism of fats and protein Hakim et al. ${ }^{31}$ as a result of cells inability to metabolize glucose 
properly (gluconeogenesis from amino acids and body protein). These metabolic derangements eventually result to muscle, tissue wasting and breakdown. This result is in agreement with the work done by Ebuehi et al. ${ }^{32} \mathrm{An}$ increase in serum GGT was observed in diabetic rats when compared to normal controls. The results were in accordance with many prospective studies like those of Lee et al.;3 Nakanishi et al. ${ }^{34}$ Sharma et al. ${ }^{35}$ who reported a strong relationship between GGT concentrations and incident diabetes. This relationship could be as a result of GGT acting as a marker of oxidative stress. Hiderani et al. ${ }^{36}$ reported that serum GGT activity may be regarded as a marker of oxidative stress rather than a mere indicator of excessive alcohol consumption or liver dysfunction, and that increased serum GGT may reflect a counter reaction of human bodies against increased oxidative stress. It has been shown that GGT counteracts oxidative stress by breaking down extracellular glutathione and making component amino acids of glutathione available to the cells Whitfield. ${ }^{37}$ In the present investigation, diabetic rats exhibited profound decrease in the serum TAC concentration when compared to the control. This could be due to increased ROS generation by mechanisms such as glucose auto-oxidation, polyol pathway and PKC activation. Evidences suggest that oxidative stress is increased in diabetes resulting from an overproduction of ROS, and decreased efficiency of antioxidant activity in the diabetic rats is indicative of oxidative stress.

The results of this study are in accordance with those of Datta et al., ${ }^{38}$ Jackson et al. ${ }^{39}$ Sait \& Hattice. ${ }^{40}$ Enas. ${ }^{23}$ reported an increase in antioxidant capacity in alloxan treated rats which he attributed to over expression of antioxidant enzymes in response to glucoseinduced oxidative stress. Serum GGT concentration was higher whereas TAC concentration was lower in diabetic rats compared to the normal control. This negative correlation between GGT and TAC could be attributed to oxidative stress in diabetes which depletes the antioxidant defense system resulting in a compensatory increase in GGT. Chronic hyperglycaemia and dyslipidaemia are associated with a variety of metabolic disorders in human and animal diabetes Handen et al. ${ }^{41}$ causing oxidative stress, depleting the activity of the antioxidant defense system and resulting in elevated levels of ROS Dahech \& Handen et al. ${ }^{42,43}$ The inverse association between antioxidants and serum GGT has indicated the possibility that serum GGT might be associated with oxidative stress Lee et al. ${ }^{44}$ Takigawa et al..$^{45}$ In the present study, HbA1c was used as a marker of glycaemic control. The significant increase in HbAlc concentration in the diabetic rats when compared to the control may be attributed to the persistent hyperglycaemia. Persistent hyperglycaemia, uncontrolled or poorly controlled diabetes results to an increased glycosylation of a number of proteins including haemoglobin because the excess glucose in blood reacts with haemoglobin. This result supports the work done by Aruna et al.; ${ }^{46}$ Muthulingam..${ }^{47}$ Neeraj et al. ${ }^{48}$ Vallejo et al. ${ }^{49}$ on higher HbA1c levels in diabetic rats. Our study also showed that alloxan-induced diabetes in rats produced alterations in the hepatic structures as well as functions while the control group showed no pathological changes. This was evident from the histological sections which showed mild and moderate periportal lymphocytic infiltrations with sinusoidal dilatations as well as serum elevation of transaminases activities (ALT and AST) which are indices of liver cell damage. These changes could be attributed to the altered architecture of the hepatocytes, and these subtle membrane changes are sufficient to allow the leakage or passage of intracellular enzymes into blood, hence their increased concentrations in serum. Moreover, cell damage increases permeability causing cytosolic isoenzymes to spill into the interstitium, and from there into the peripheral blood. The pathological changes in liver of alloxan and streptozotocin induced diabetic animals have been previously reported Herrman \& Sandhu et al..$^{50,51}$ Zhang et al. ${ }^{52}$ reported an increased serum levels of ALT and AST in diabetic rats. Ohaeri, ${ }^{53} \mathrm{Al}$-shamshi et al. ${ }^{54}$ Fadillioglu et al. ${ }^{55}$ also reported an increased serum ALT and AST in diabetes patients than in the general population (Figures 1-4).

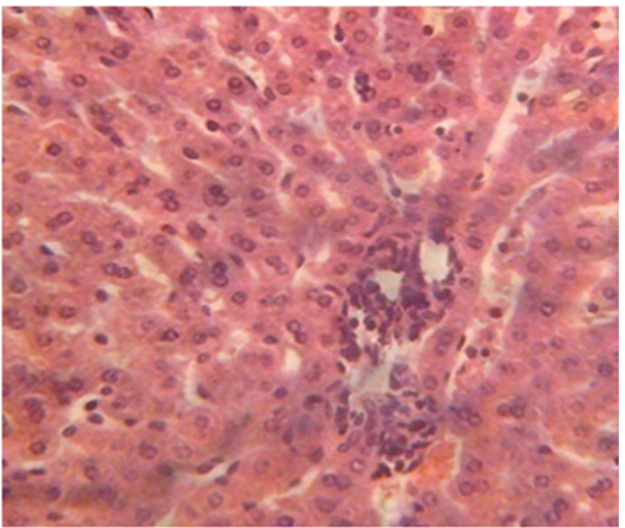

Figure I Liver micrograph of control rat showing at 3 and 5 weeks. ( $\mathrm{H}$ \& E stain X400).

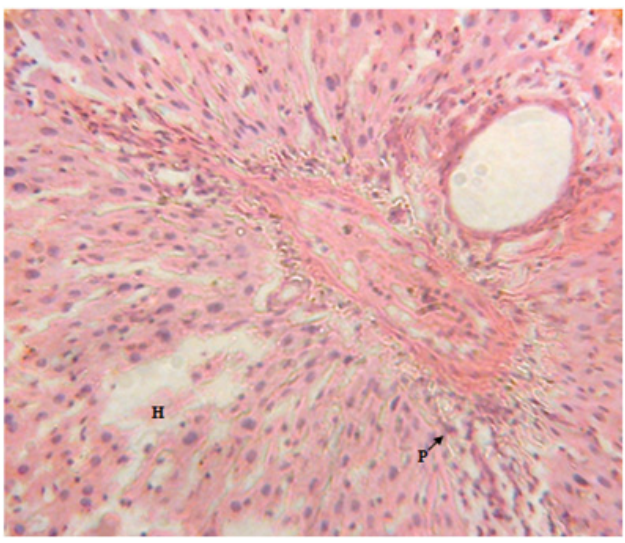

Figure 2 Liver micrograph of diabetic rat showing mild periportal lymphocytic infiltration $(\mathrm{P})$ and hepatocyte disorientation $(\mathrm{H})$ at 3 weeks. $(\mathrm{H}$ \& $E$ stain X400).

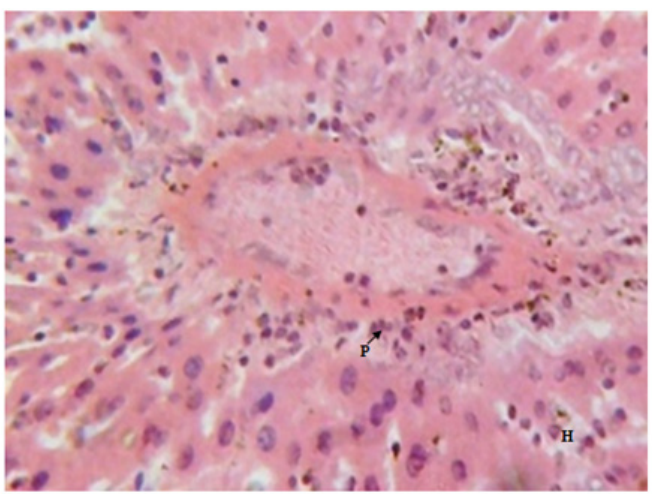

Figure 3 Liver micrograph of diabetic rat showing moderate periportal lymphocytic infiltration $(\mathrm{P})$ and hepatocyte disorientation $(\mathrm{H})$ at 5 weeks. $(\mathrm{H}$ \& $E$ stain $X 400)$. 


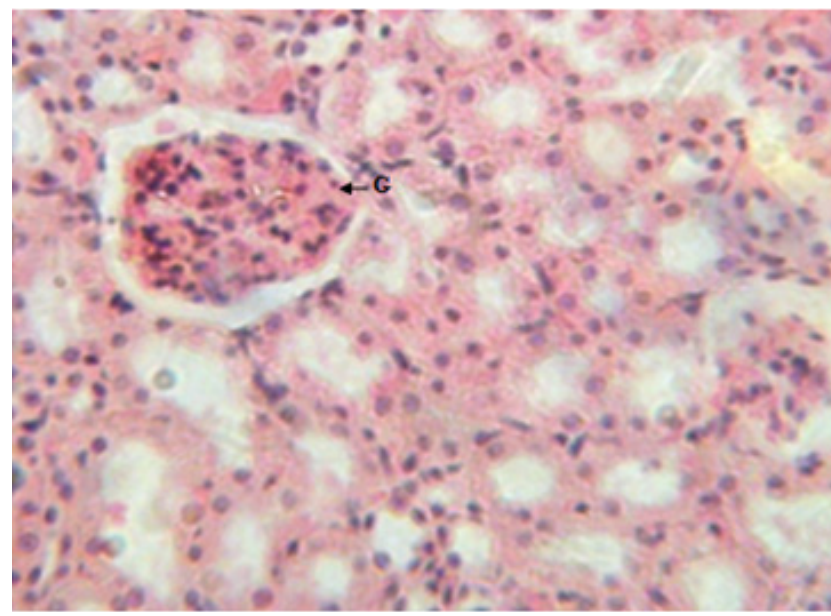

Figure 4 Kidney micrograph of control rat showing normal glomerular(G) structure at 3 and 5 weeks. (H \& E stain X400).

The results of this study however disagree with the results of Jianpu et al..$^{56}$ who reported that serum ALT and AST levels in diabetic rabbits were within normal ranges and Gidado et al. ${ }^{21}$ who reported insignificant changes in serum levels of ALT and AST in diabetic rats. The liver is one of the tissues that bear the brunt of chronic hyperglycaemia, since glucose is freely permeable to its cells Meyes. ${ }^{57}$ This unrestrained entry, in the presence of excess and sustained glucose in the blood is bound to cause metabolic derangements which would express themselves on the gross architecture of the tissues Atangwho et al. ${ }^{58}$ Present observations on the diabetic rat kidneys showed a progressive damage which increased with duration and severity of hyperglycemia as recorded by Muhammad et al. ${ }^{59}$ the resultant renal damage was caused by severe hyperglycemia induced by alloxan. There were septal haemorrhages, glomerular degeneration, increased capsular space with tubular epithelial damage and dysplasia as observed in kidney sections of the diabetic rats. These findings are in agreement with the findings of Kim et al.; ${ }^{60}$ Muhammad et al. ${ }^{59}$ Renno et al. ${ }^{61}$ who showed tubular epithelial changes and enlargement of lining of cells of the tubules (Figures 5-11).

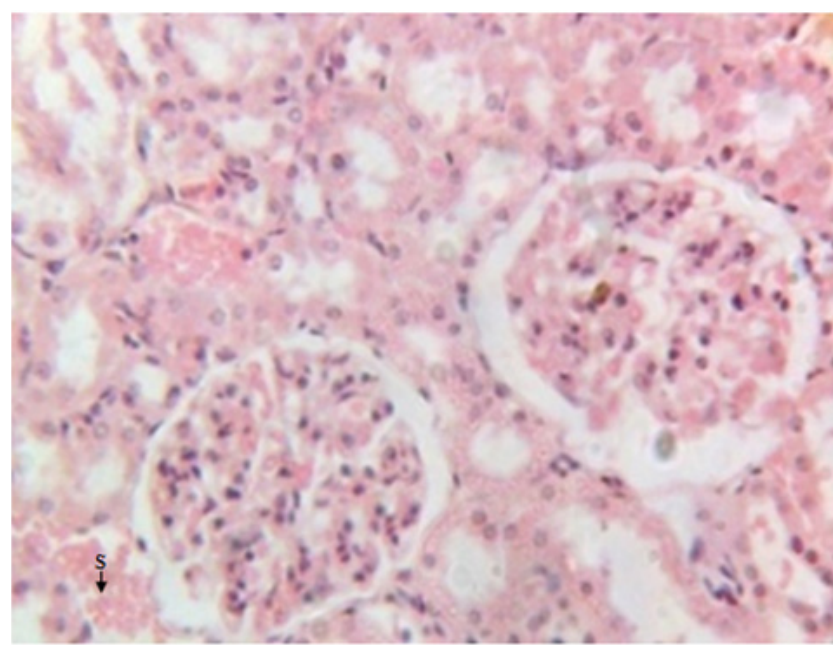

Figure 5 Kidney micrograph of diabetic rat showing septal haemorrhage(S) at 3 weeks. (H \& E stain X400).

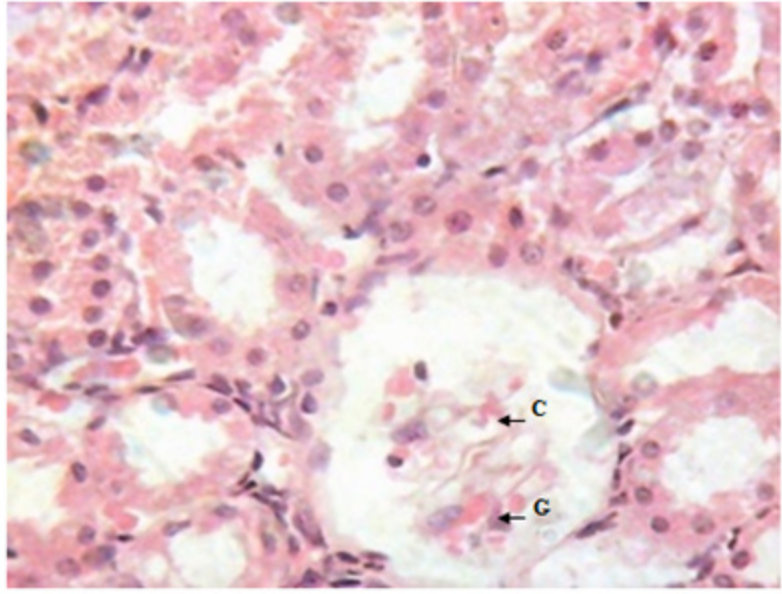

Figure 6 Kidney micrograph of diabetic rat showing glomerular degeneration $(\mathrm{G})$ and increased capsular space $(\mathrm{C})$ at 5 weeks. (H \& E stain X400).

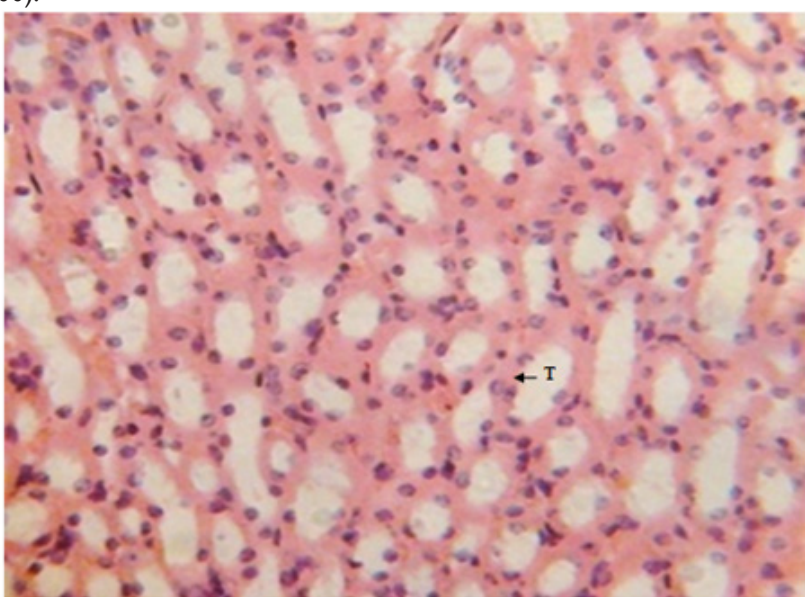

Figure 7 Kidney micrograph of control rat showing normal tubular(T) structures at 3 and 5 weeks. (H \& E stain X400).

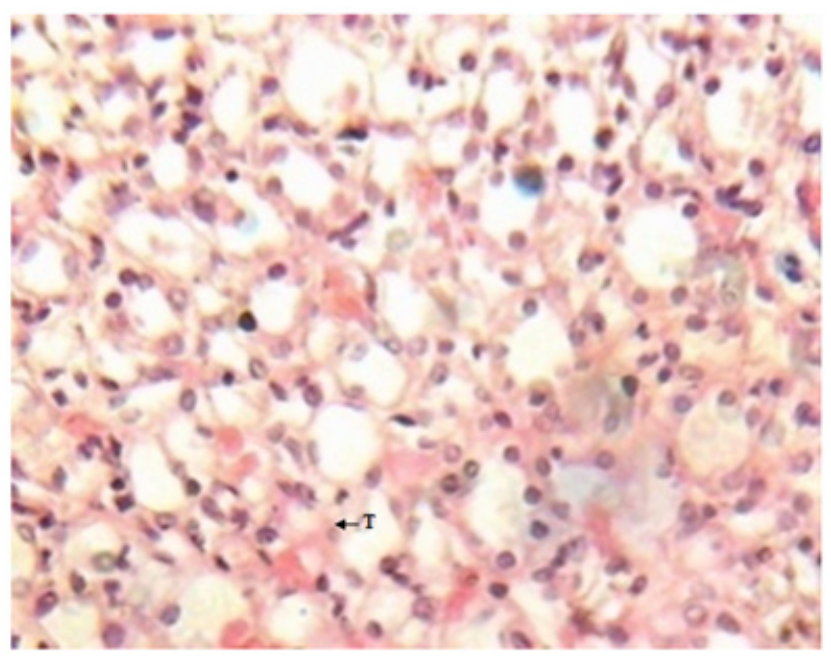

Figure 8 Kidney micrograph of diabetic rat showing mild tubular damage(T) at 3 weeks. (H \& E stain X400). 


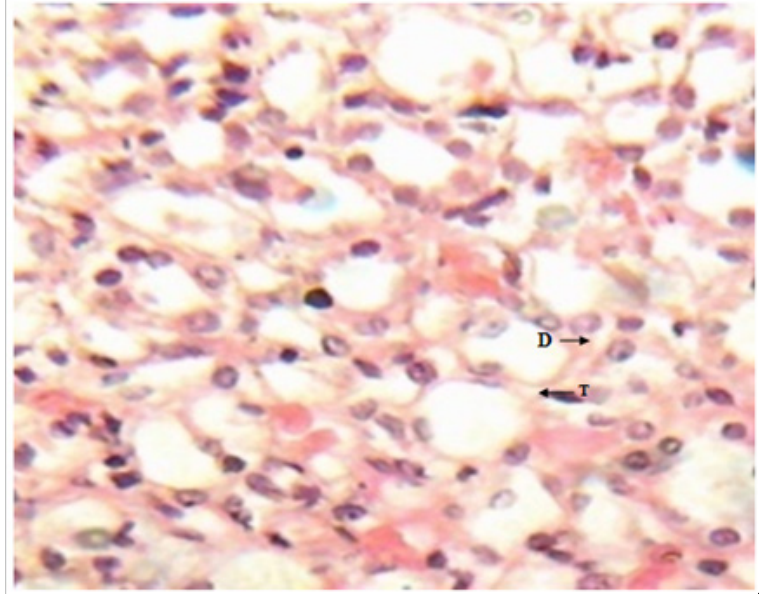

Figure 9 Kidney micrograph of diabetic rat showing moderate tubular damage(T) and dysplasia(D) at 5 weeks. (H \& E stain X400).

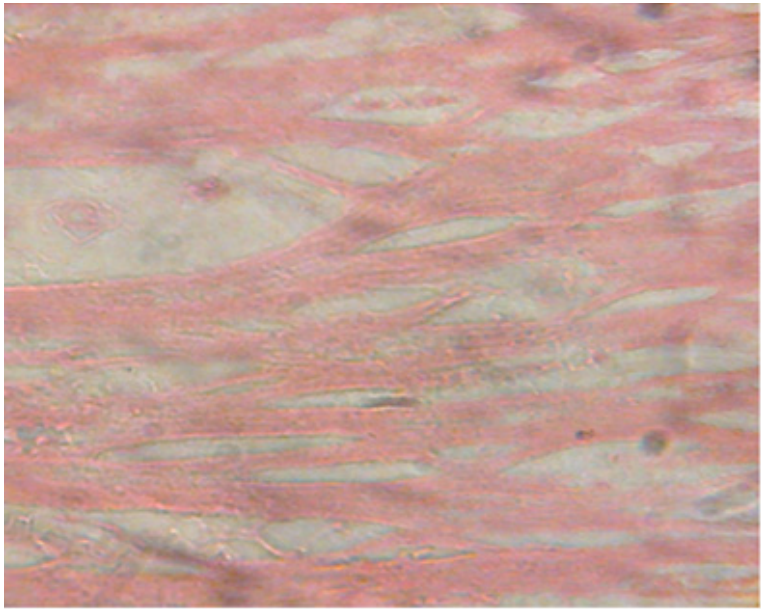

Figure 10 Heart micrograph of control rat showing normal cardiac muscle structures at 3 and 5 weeks.

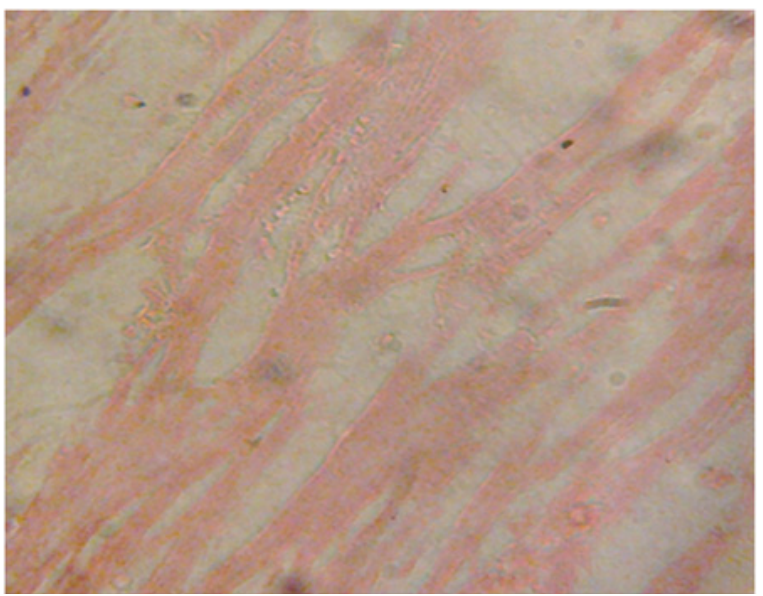

Figure I I Heart section of diabetic rat showing no alterations of the cardiac muscle structures at 3 and 5 weeks.

The structural changes in the kidneys could be attributed to altered metabolism in diabetes Rasch, ${ }^{62}$ and subsequent effects on the increased renal threshold for hyperglycemia. ${ }^{29}$ Moreover, glucose overload damages the mesangial cells in the renal glomerulus through oxidative stress Brownlee. ${ }^{63}$ In the diabetic kidney, enhanced glucose uptake occurs in many cell populations including glomerular epithelial cells, mesangial cells and proximal tubular epithelial cells leading to the excessive production of intracellular ROS, making these cells particularly susceptible to diabetic milieu Forbes et al.; ${ }^{64}$ Eze ${ }^{65}$ reported some degeneration of glomeruli with presence of tubular casts and signs of chronic inflammation in diabetic wistar rats. Peter et al. ${ }^{66}$ had previously reported a damaging effect of diabetes in the glomerulus, thereby affecting Glomerular Filtration Rate (GFR). Zafar et al ${ }^{67}$ also reported that streptozotocin-induced diabetic rats showed some functional and morphological changes in the kidney. These morphological abnormalities in the kidney of diabetic rats were associated with significant elevations in serum urea and creatinine levels, indicating impaired renal function of the diabetic animals. The results are consistent with those of Shah et al..$^{68}$ who reported elevated serum urea and creatinine levels as a result of renal damage in diabetic rats. The histological sections of the hearts of diabetic as well as nondiabetic rats showed normal architecture of the myocardium for the study period. This is consistent with the work done by Kita et al. ${ }^{69}$ who reported short-term metabolic disorders in diabetic rat heart with histopathological changes occurring later. The results disagree with those of Komolafe et al. ${ }^{24}$ who reported architectural alterations in myocardium and microanatomy of cardiovascular structures of diabetic animals. In the present study, serum lipid profile was used to assess the risk of development of cardiovascular disease which recorded elevated total cholesterol, LDL-C, VLDL-C and triglyceride levels whereas HDL-C levels decreased in alloxan-induced diabetic rats which is associated with cardiovascular diseases as seen in diabetes. The abnormal high levels of serum lipids in diabetes is mainly due to increased activity of hormone sensitive lipase in insulin deficiency resulting in enhanced lipolysis and mobilization of free fatty acids from the peripheral depots and adipose due to underutilization of glucose. Some of the excess fatty acid produced is then metabolized to acetyl coA which is used in the synthesis of cholesterol in the liver, thus increasing cholesterol levels in diabetes. On the other hand, glucagon, catecholamines and other hormones may also enhance lipolysis. Therefore, the uninhibited action of lipolytic hormones on the fat depots may be responsible for this increase. The lack of insulin and elevations of counter regulatory hormones lead to activation of enzyme (hormone-sensitive lipase) that stimulate lipolysis and enhance release of free fatty acids from adipose tissue. The fatty acids from adipose tissues are mobilized for energy purpose, and excess fatty acids are accumulated in the liver, which are converted to triglycerides Suryawanshi et al. ${ }^{70}$ The high levels of LDL-C may be attributed to diminished levels of LDL receptors resulting in increased circulating LDL particles Suryawanshi et al. ${ }^{70}$ The decreased serum HDL-C levels in the present study may enhance CVD risk since HDL-C function is to remove cholesterol atheromas within arteries and transport them back to the liver for excretion and re-utilization. The results support the works of ${ }^{21,23,24,40,68}$ who reported marked increase in cholesterol, triglycerides, LDL-C, VLDL-C and decreased HDL-C in diabetic rats when compared to non-diabetic rats. However, Jos et al. ${ }^{71}$ reported no correlation between diabetes mellitus and lipids in the study conducted with diabetes patients.

\section{Conclusion}

From our study, alloxan-induced diabetes caused an elevation of serum GGT and decreased total antioxidant levels which suggest that 
GGT and TAC may be used as reliable markers of oxidative stress in diabetes mellitus. The pathologic lesions and various alterations in the biochemical markers of liver and kidney functions resulting in their structural and functional abnormalities may be regarded as oxidative stress-induced diabetic complications in these organs. It may also be concluded that the effect of diabetes on the heart results in metabolic and biochemical disorders which may eventually lead to morphological changes at a later stage of the disease.

\section{Acknowledgment}

The study was sponsored by all the authors.

\section{Conflict of interests}

The authors have declared that no competing interests exist.

\section{References}

1. American Diabetes Association. Standards of Medical care in diabetes. Diabetes Care. 2004;27(suppl 1):S15-S35.

2. Nigel Unwin, David Whiting, et al. International Diabetes Federation Diabetes Atlas. 5th ed. Brussels: Belgium; 2011.

3. Ghaisas M, Navghare V, Takawale A, et al. Journal of Ethnopharmacology. 2009;122:304-307.

4. Gavin N Levinthal, Tavill AS. Liver disease and diabetes mellitus. Clinical Diabetes. 1999;17:1-17.

5. Quan N, Ho E, La W, et al. Administration of nuclear factor-kappa $\mathrm{B} \mathrm{NF}-\mathrm{kB}$ decoy inhibits pancreatic activation of NF-kB and prevents diabetogenesis by alloxan in mice. Journal of the Federation of American Societies for Experimental Biology. 2001;15:1616-1618.

6. Bell RH Jr, Hye RJ. Animal models of diabetes mellitus: Physiology and Pathology. J Surg Res. 1983;35(5):433-460.

7. Ames BN, Shigenaga MK, Hagen TM. Oxidants, antioxidants and the degenerative diseases of aging. Proc Natl Acad Sci USA. 1993;90(17):7915-7922.

8. Yu BP. Cellular defenses against damage from Reactive Oxygen Species. Physiol Rev. 1994;74(1):139-162.

9. Trinder PL. Blood glucose measurement. Annals of Clinical Biochemistry. 1969;6:23-24.

10. Fabing DL. Ertingshaushen G. Serum creatinine estimation. Clinical Chemistry. 1971;17:696-700.

11. Rietman S, Frankel S. Serum transaminases measurement. American Journal of Clinical Pathology. 1954;28:36-40.

12. Richmond N. Estimation of serum cholesterol. Clinical Chemistry. 1973;19:1350-1356.

13. Roeschlau P, Bernt E, Gruber J.W (1974); Clinical Chemistry and Clinical Biochemistry. 12:403-405.

14. Warnick GR, Albers JJ. A comprehensive evaluation of the heparin manganese precipitation procedure for estimating high density lipoprotein cholesterol. J Lipid Res. 1978;19:65-76.

15. Tietz NW. Clinical guide to laboratory tests, $2^{\text {nd }}$ ed. Philadelphia, USA WB Saunders Company; 1990:554-556.

16. Friedewald WT, Levy RI, Fredrickson DS. Estimation of concentration of low density lipoprotein cholesterol in plasma without the use of preparative ultracentrifuge. Clin Chem. 1972;18(6):449-452.
17. Persijn JP, Van der Slik W. A new method for the determination of gamma glutamyl transferase in serum. J Clin Chem Clin Biochem. 1976;9(14):421-427.

18. Gendler S, Kaplan A. Gamma glutamyl transferase. Clinical Chemistry. St Louis, Toronto: CV Mosby Co; 1984; 1120-1123.

19. Koracevic D, Koracevic G, Djordjevic V, et al. Method for the measurement of antioxidant activity in human fluids. $J$ Clin Pathol. 2001;54(5):356-361.

20. Bissé E, Abraham EC. New less temperature-sensitive microchromatographic method for the separation and quantitatoin of glycosylated haemoglobin using anion-cyanide buffer systems. $J$ Chromatogr. 1985;344:81-91.

21. Gidado A, Ameh DA, Atawodi S, et al. Antidiabetic Pharmacognosy Research. 2009;1(6):392-395.

22. Gwarzo MY, Nwachukwu VA, Lateef AO, et al. Prevention of alloxaninduced diabetes mellitus in rats by vitamin A dietary supplementation. Asian Journal of Animal Sciences. 2010;4(4):190-196.

23. Enas Ali KM. Antidiabetic, antihypercholestermic and antioxidative effect of Aloe vera gel extract in alloxan-induced diabetic rats. Australian Journal of Basic and Applied Sciences. 2011;5(11):13211327.

24. Komolafe AO, Adeyemi DO, Adewole OS, et al. Morphological \& morphometric studies of aorta, pulmonary trunk and heart of streptozotocin-induced diabetic wistar rats. Folia morphology. 2009;68(4):207-214.

25. Murali B, Upadhyaya UM, Goyal RK, et al. Effect of chronic treatment with Enicosistemma littorale in non-insulin-dependent diabetic rats. Journal of Ethnopharmacolgy. 2002;81(2):199-204.

26. Urmila AS, Goyal RK. Effect of chromium picolinate on histopathological alterations in streptozotocin and neonatal diabetic rats. J Cell Mol Med. 2003;7(3):322-329.

27. Sandhu K, Randhawa SS, Brar RS, et al. Clinical and pathological changes in alloxan-induced diabetes mellitus alone and in combination with ethylene glycol-induced nephropathology in dogs. Indian Journal of Veterinary Pathology. 2000;24:12-15.

28. Szkudelski T. The mechanism of alloxan and streptozotocin action in cells of the rat pancreas. Physiol Res. 2001;50(6):536-546.

29. Mir SH, Baqui A, Darzi MM, et al. Pathoantomy of experimental diabetes in rabbits (Oryctolagus cuniculus). Oriental Science. 2006;11:69-72.

30. Muthulingan M. Antidiabetic efficacy of leaf extracts of Asteracantha longifolia (Linn) Nees on alloxan-induced diabetes in male albino wistar rats. Biomedical Research. 2010;1(2):28-34.

31. Hakim ZC, Patel BK, Goyal RK. Effect of chronic ramipril treatment in streptozotocin-induced diabetic rats. Indian J Physiol Pharmacol. 1997;41(4):353-360.

32. Ebuehi OAT, Ajuluchukwu AE, Afolabi OT, et al. Oxidative stress in alloxan-induced diabetes in female \& male rats. Advances in Medical and Dental Sciences. 2010;3(3):71-75.

33. Lee DH, Jacobs DR, Gross M, et al. Gamma glutamyl transferase is a predictor of incident diabetes and hypertension: the Coronary Artery Risk Development in Young Adults (CARDIA) study. Clinical Chemistry. 2003;49(8):1358-1366.

34. Nakanishi N, Nishina K, Li W, et al. Serum gamma glutamyl transferase and development of impaired fasting glucose or type 2 diabetes in middle aged Japanese men. Journal of Internal Medicine. 2003;254(3):287-295. 
35. Sharma R, Sharma S, Kaushik GG, et al. Gamma glutamyl transferase-a novel marker of endothelial dysfunction. Journal of Indian Academy of Clinical Medicine. 2010;11(1):26-30.

36. Hiderani S, Takashi S, Hiroko Y, et al. Gamma glutamyl transferase and metabolic risk factor for cardiovascular disease. Internal Medicine. 2005;44:(6)538-541.

37. Whitfield JB. Gamma glutamyl transferase. Crtical Reviews in Clinical Laboratory Sciences. 2001;38(4):263-355.

38. Datta K, Sinha S, Chattopadhy AY, et al. Immunocytochemical evidence that amyloid beta 1-42 impairs endogenous auto-oxidant system in vivo. Neuroscience. 2000;199:399-419.

39. Jackson M, Xia J, Jing C, et al. Protection against oxidative stress in diabetic rats by wheat bran feruloyl oligosaacharides. Journal of Agricultural and Food Chemistry. 2007;55:3191-3195.

40. Sait C, Hatice A. Total Antioxidant Concentration, catalase and superoxide dismutase of rats before and after diabetes. Journal of Animal \& Veterinary Advances. 2009;8(8):1503-1508.

41. Handen K, Ayadi F, Jamoussi K, et al. Therapeutic effect of phytoecdysteroids rich extract from Ajuga iva on alloxan-induced diabetic rats liver, kidney and pancreas. Biofactors. 2008;33(3):165175 .

42. Dahech I, Belghith KS, Hamden K, et al. Antidiabetic activity of levan polysaccharide in alloxan-induced diabetic rats. International Journal of Biological Macromolecules. 2011;49(4):742-746.

43. Handen K, Jaouadi B, Zarai N, et al. Inhibitory effects of estrogens on digestive enzymes, insulin deficiency, and pancreas toxicity in diabetic rats. Journal of Physiology and Biochemistry. 2011;67(1):121-128.

44. Lee DH, Gross MD, Jacobs DR, et al. Cardiovascular risk development in young adults study. Clinical Chemistry. 2004;50(3):582-588.

45. Takigawa T, Hibino Y, Kimura S, et al. Association between serum gamina-glutamyl transferase and oxidative stress related factors. Hepatogastroenterology. 2008;55(81):50-53.

46. Aruna RV, Ramesh B, Kartha VN, et al. Effect of beta-carotene on protein glycosylation in alloxan-induced diabetic rats. Indian Journal of Experimental Biology. 1999;37(4):399-401.

47. Muthulingan M. Antidiabetic efficacy of leaf extracts of Asteracantha longifolia (Linn) Nees on alloxan-induced diabetes in male albino wistar rats. Biomedical Research. 2010;1(2):28-34.

48. Neeraj V, Amresh G, Sahu PK, et al. Anti-hyperglycaemic and antihyperlipidaemic activity of ethyl acetate fraction of Rhododendron arboreum smith flowers in streptozotocin-induced diabetic rats and its role in regulating carbohydrate metabolism. Asian Pacific Journal of Tropical Biomedicine. 2012;2(9): 696-701.

49. Vallejo S, Angulo J, Pieiro C, et al. Treatment with acarbose may improve endothelial dysfunction in streptozotocin-induced diabetic rats. Journal of Cardiovascular Pharmacology. 2000;36(2):255-262.

50. Herrmann CE, Sander RA, Klaunig JE, et al. Decreased apoptosis as a mechanism for hepatomegaly in streptozotocin-induced diabetic rats. Toxicological Sciences. 1999;50(1):146-151.

51. Sandhu K, Randhawa SS, Brar RS, et al. Clinical and pathologica changes in alloxan-induced diabetes mellitus alone and in combination with ethylene glycol-induced nephropathology in dogs. Indian Journal of Veterinary Pathology. 2000;24:12-15.

52. Zhang A, Vetronmenn J, VanGaal L, et al. Effects of Pravastatin on lipid levels in vitro oxidizability of non-HDL lipoproteins and microalbuminuria in Insulin Dependent Diabetes Mellitus Patients. Diabetes Research and Clinical Practice. 1995;29(3):189-194.
53. Ohaeri OC. Effect of garlic oil on the levels of various enzymes in serum and tissues of streptozotocin diabetic rats. Bioscience Report. 2001;21(1):19-24.

54. Al Shamsi M, Amin A, Adeghate E, et al. Vitamin E ameliorates some biochemical parameters in normal and diabetic rats. Ann N Y Acad Sci. 2006;1084:411-431.

55. Fadilloglu E, Kurcer Z, Parlakpinar H, et al. Melatonin treatment against remote open injury induced by renal ischaemia reperfusion injury in diabetes mellitus. Archives of Pharmacal Research. 2008;31(6):705712 .

56. Jianpu W, Rong W, Yiqun M, et al. Creating a long-term diabetic rabbit model. Experimental Diabetes Research. 2010;1-10.

57. Meyes PA. Gluconeogenesis \& control of blood glucose. In Harper's Biochemistry. New York: McGraw-Hill; 2003. pp.208-218.

58. Atangwho IJ, Ebong PE, Egbung GE, et al. Histological effect of combined extracts of Veronica amygdalina \& Azadirachta indica on normal and diabetic rats: the pancreas \& liver. Research Journal of Agriculture \& Biological Sciences. 2010;6(4):514-521.

59. Muhammad Z, Syed NN, Masood A, et al. Altered kidney morphology and enzymes in streptozotocin-induced diabetic rats. International Journal of Morphology. 2009;27(3):783-790.

60. Kim HJ, Kong MK, Kim YC, et al. Beneficial effects of Phellodendri cortex extract on hyperglycaemia and diabetic nephropathy in streptozotocin-induced diabetic rats. Biochemistry and Molecular Biology Reports. 2008;41(10):710-715.

61. Renno W, Abdeen S, Alkhalaf M, et al. Effect of green tea on kidney tubules of diabetic rats. Britain Journal of Nutrition. 2008;100(3):652659 .

62. Rasch. Prevention of diabetic glomerulopathy in streptozotocin diabetic rats by insulin treatment. Glomerular basement membrane thickness. Diabetologia. 1979;16(5):319-324.

63. Brownlee M. Biochemical and Molecular cell biology of diabetes complications. Nature. 2001;414:813-820.

64. Forbes JM, Coughlan MT, Cooper ME, et al. Oxidative stress as a major culprit in kidney disease in diabetes. Diabetes. 2008;57(6):1446-1454

65. Eze KN. The Renoprotective effect of coconut water on the kidneys of diabetic wistar rats. Journal of Health Sciences. 2012;2(1):1-4.

66. Peters AM, Glass DM. Use of Body Surface Area for Assessing Extracellular Fluid Volume and Glomerular Filtration Rate in Obesity. American Journal of Nephrology. 2010;31(3):209-213.

67. Zafar M, Naqvi SN, Ahmed M, et al. Altered kidney morphology \& enzymes in streptozotocin-induced diabetic rats. International Journal of Morphology. 2009;27(3):783 -790.

68. Shah JG, Patel MS, Patel KV, et al. Evaluation of anti-diabetic and antioxidant activity of Centratherum anthelmintica in streptozotocininduced diabetic rats. The Internet Journal of Pharmacology. 2008;6(1).

69. Kita Y, Shimizum, Sugihara N, et al. Correlation between histopathological changes and mechanical dysfunction in diabetic rat hearts. Diabetes Res Clin Pract. 1991;11(3):177-188.

70. Suryawanshi NP, Bhutey AK, Nagdeote AN, et al. Study of lipid peroxide \& lipid profile in diabetes mellitus. Indian Journal of Clinical Biochemistry. 2006;21(1):126-130.

71. Jos J, Kybak M, Patin PH, et al. Etude des enzymes antioxidants dans lediabete insulin independence de 1' enfant et de 1' addescent. Diabete et Metabolisme. 1990;16:498-503. 